\title{
Evaluation of Fracture Toughness Measurements Using Chevron-Notched Silicon and Tungsten Microcantilevers
}

\author{
B.-S. LI, ${ }^{1,2}$ T.J. MARROW,${ }^{1}$ S.G. ROBERTS,${ }^{1}$ and D.E.J. ARMSTRONG ${ }^{1}$ \\ 1.-Department of Materials, University of Oxford, Oxford OX1 3PH, UK. 2.-e-mail: bo-shiua- \\ n.li@materials.ox.ac.uk
}

\begin{abstract}
Measuring the fracture behavior of small specimens of semibrittle materials such as tungsten is often difficult due to the lack of crack stability and a high ratio of the crack tip plastic zone size to specimen dimensions. To overcome this, microcantilever bending tests were used with a stable chevron notch geometry coupled with elastic-plastic fracture mechanical (EPFM) analysis. The chevron notch geometry was first validated by measurement of the (111) cleavage toughness in single-crystal $\mathrm{Si}$, then fracture resistance curves $(R$ curves) were calculated via EPFM analysis of fracture data obtained from a semibrittle $\mathrm{W}-1 \% \mathrm{Ta}$ alloy. The accuracy of the fracture resistance curves measured from W-1\% Ta was evaluated by means of ASTM standard macroscopic fracture tests. The conditional fracture toughness $\left(K_{\mathrm{Qc}}\right)$ prior to crack instability was found to be five times larger than the macroscopic fracture toughness $\left(K_{\mathrm{Ic}}\right)$, due to the combination of plastic tearing of ductile ligaments and the extensive microplasticity ahead of the crack tip. These results suggest that use of chevron-notched microcantilevers is suitable for evaluating the fracture toughness of brittle silicon but overestimates the fracture toughness value for semibrittle tungsten.
\end{abstract}

\section{INTRODUCTION}

Fracture testing using focused-ion beam (FIB)fabricated microspecimens loaded by nanoindentation is now an established technique for investigating fracture behavior at microscale. ${ }^{1-3}$ Microfracture tests can bring the benefit of testing the fracture properties of individual microstructural constituents, such as grain boundaries, or significantly reducing the radiated volume when dealing with neutron-irradiated samples. ${ }^{4,5}$ Among microfracture specimen designs, the prenotched microcantilever has gained in popularity due to its rather simple fabrication and straightforward fracture mechanical analysis. ${ }^{6-9}$ Other microfracture specimen designs, such as pillars, ${ }^{10}$ double cantilevers, ${ }^{11}$ double-clamped beams, ${ }^{12}$ and doubleedged notched tensile bars, ${ }^{13}$ have also been developed. The applicability of each microspecimen design usually depends on the brittleness of the material and features of interest. A round-robin study of tests using various microfracture specimen designs for purely brittle materials was conducted by Jaya et al. ${ }^{14}$ on silicon. The measured plane- strain fracture toughness $\left(K_{\text {Ic }}\right)$ values were within the range of $0.7 \mathrm{MPa} \mathrm{m}{ }^{0.5}$ to $1.2 \mathrm{MPa} \mathrm{m}^{0.5}$, in good agreement with the macroscopic value of $\sim 1 \mathrm{MPa} \mathrm{m}^{0.5}{ }^{15}$

Microfracture studies have largely focused on intrinsically brittle materials, for which linearelastic fracture mechanical (LEFM) analysis is applicable due to the small ratio of the crack tip plastic zone size to specimen dimensions. However, for metallic materials, the crack tip plastic zone size can range from a few microns to hundreds of microns, which becomes significant in comparison with the specimen dimensions. LEFM analysis then underestimates the true fracture toughness due to its neglect of the localized crack tip plastic deformation. Elastic-plastic fracture mechanical (EPFM) analysis, on the other hand, provides a more complete quantification of the plasticity-associated fracture process. Wurster et al. ${ }^{16}$ performed the first elastic-plastic microfracture tests on prenotched single-crystal tungsten cantilevers. The cantilevers were deformed in situ in a scanning electron microscope (SEM) using a displacement-controlled nanoindenter. Both load-displacement data and 
SEM images were used to record the crack extension during testing and to inform the EPFM analysis. Ast et al. ${ }^{17}$ performed microfracture tests using single-crystal $\mathrm{NiAl}$ cantilevers. Cantilever stiffness values from cyclic and dynamic loading were used to calculate the $J$-integral EPFM parameter. Both works showed pronounced fracture resistance behavior ( $R$-curve) during crack growth in these semibrittle materials. Ast et al. ${ }^{18}$ later performed in situ single-crystal tungsten microcantilever tests coupled with high-resolution electron backscatter diffraction (HR-EBSD) analysis. This combination of techniques allowed experimental validation of the crack tip plastic zone size during cantilever bending tests and confirmed that EPFM is a more suitable fracture mechanical analysis method than LEFM to quantify the plasticity-assisted fracture process. One should also note that Ast used straight prenotches, hence the notch bluntness and lack of crack stability during the initial stage of crack growth may have influenced the fracture toughness measurements.

The most important prerequisite for EPFM analysis under quasistatic loading is unambiguous crack stability. However, this is difficult to achieve in microfracture experiments due to several factors: (1) most nanoindenters are intrinsically load controlled, (2) FIBed prenotches are rather blunt compared with real fatigue cracks or other atomically sharp ideal cracks, so an overload may be required to start crack propagation, and (3) most microfracture tests are conducted in bending mode, which is an unstable geometry for crack propagation. Possible solutions are to utilize an inherently stable specimen geometry, e.g., a double-cantilever beam, or to use a displacement-controlled loading apparatus. Liu et al. ${ }^{11}$ achieved stable cracking by compressing a prenotched micro double-cantilever beam (DCB) with a flat punch. However, only the critical load at crack instability was used in that work, and the fracture toughness calculation was based on LEFM. Sernicola et al. ${ }^{19}$ extended the DCB approach by using a displacement-controlled indenter to facilitate stable crack growth and an energy-based fracture mechanical analysis to calculate the $R$-curve. This method relied on an in situ SEM experiment where crack length could be measured directly. However, several issues remain in the DCB approach, including: (1) the non-freestanding geometry, (2) friction between the indenter and specimen surface, and (3) the interaction between the crack tip and indentation stress field.

These issues are not present with cantilever specimens, so an alternate method is to change the notch geometry to one that promotes initial stable crack growth in cantilever bending experiments (e.g., a chevron notch). Mueller et al. ${ }^{20}$ were the first to utilize the crack stability provided in chevron notches in microcantilever fracture experiments. The materials chosen for validation (fused quartz and alumina) were inherently brittle, so crack tip plasticity was very limited and LEFM was sufficient to calculate valid fracture toughness values. Chevron notches were used to initiate and stabilize sharp precracks, which effectively reduced the notch root effect and the possible galliumintroduced amorphization at the crack tip. ${ }^{21}$

In this work, chevron-notched microcantilevers were used to initiate sharp precracks and provide stability for EPFM analysis of quasistatic crack propagation in a semibrittle material. First, singlecrystal silicon microcantilevers and finite-element (FE) modeling were used to validate the stress intensity factors (SIFs) of this specimen design and guide the chevron notch geometry. Microcantilevers were then fabricated in semibrittle tungsten-1wt\% tantalum (W-1\% Ta) alloy and tested by using a modified load partial-unload method. The $R$-curves and conditional fracture toughness $\left(K_{\mathrm{Qc}}\right)$ values were evaluated using the macroscopic fracture toughness $\left(K_{\mathrm{Ic}}\right)$ and ASTM standard E1820 to calculate the minimum microscopic specimen size required to provide valid data for the elastic-plastic fracture toughness.

\section{EXPERIMENTAL PROCEDURES}

\section{Materials}

High-purity (99.99\%) single-crystal silicon from Goodfellow ${ }^{\circledR}$ (Huntingdon, UK) was used to produce specimens to validate the chevron notch design. A matchstick sample was cut via electrical discharge machining (EDM) from industrial-grade tungsten$1 \%$ tantalum (W-1\% Ta) alloy produced by Plansee ${ }^{\circledR}$ (Reutte, Austria) via powder consolidation and hot forging. Both materials were mechanically ground using SiC grit papers, followed by diamond paste polishing. Lastly, the samples were chemomechanically polished using colloidal silica to obtain a stress-free surface for electron backscattered diffraction (EBSD) analysis. Figure 1a and b shows that the grains of the $\mathrm{W}-1 \% \mathrm{Ta}$ matchstick were elongated in the $\mathrm{S}-\mathrm{T}$ orientation due to the directional hot forging, and the grains are more equiaxed in the L-S orientation. Microcantilevers were fabricated in S-T orientation so that several grains (usually 5-7) could be included in a single microcantilever.

\section{Experimental Methods}

A dual-beam Zeiss ${ }^{\circledR}$ Auriga FIB/SEM was used to fabricate the microcantilevers. For initial U-shape trenches, a milling current of $4 \mathrm{nA}$ was used; this was then reduced to $1 \mathrm{nA}, 600 \mathrm{pA}$, and finally $100 \mathrm{pA}$ for the undercuts and final polishing. For the chevron notching, the current was reduced to $10 \mathrm{pA}$ to prevent gallium-induced displacement damage. Details of the notching procedures and EBSD SEM images of a typical chevron-notched W$1 \%$ Ta microcantilever are shown in Fig. 1c and f. A G200 Nanoindenter (KLA, USA) equipped with a 


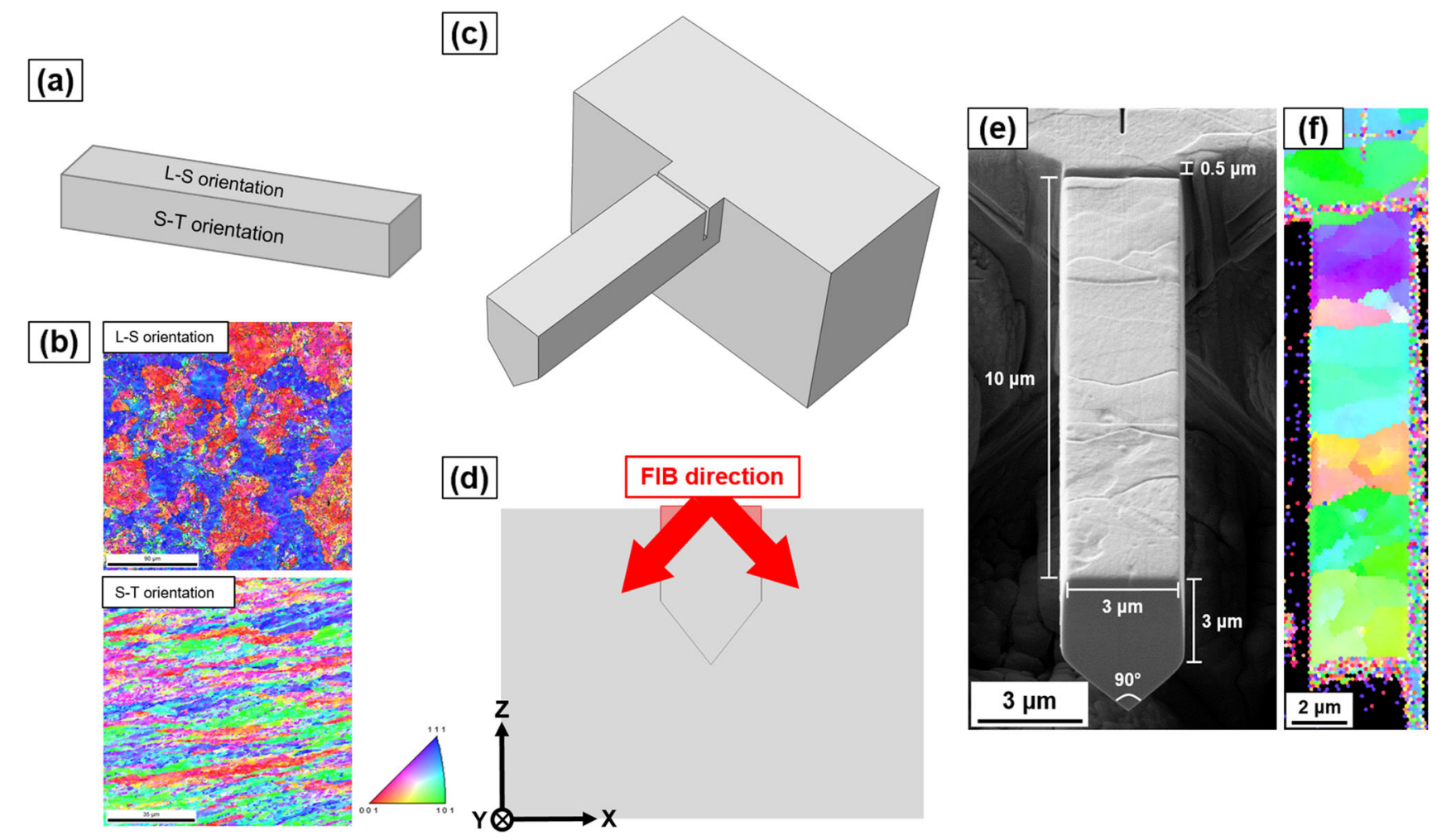

Fig. 1. (a) W-1\%Ta matchstick EDMed from the hot-forged ingot, (b) EBSD maps of both L-S and S-T orientation, (c-e) schematic of final chevron notching procedure and typical cantilever geometry, and (f) EBSD map of typical cantilever.

NanoVision ${ }^{\circledR}$ stage was used to test the microcantilevers. Each microcantilever was first scanned under the indenter tip to produce a topological image, which allowed accurate load positioning. The beams were then deflected using a load partialunload method to measure the static cantilever stiffness and work of fracture (WOF).

\section{FINITE ELEMENT MODELING OF CHEVRON-NOTCHED MICROCAN- TILEVERS}

\section{D Modeling of Chevron-Notched Microcan- tilevers}

The geometry-dependent stress intensity factors (SIFs) and cantilever stiffness values were calculated numerically using ABAQUS ${ }^{\mathrm{TM}}$ CAE 6.14 (Dassault Systems, France). A typical meshed 3D half-cantilever model and boundary conditions are shown in Fig. 2a, and dimensions are presented in Table I. The supporting base was included to take into account the base deformation; and to improve computational efficiency, only half of the cantilever was modeled and the chevron notch width was assumed to be zero. The mesh used solid 3D 20-node quadratic-type elements (C3D20R), to provide sufficient accuracy in the stress concentrated regions. A half-cantilever model with the geometry described in Table II contains approximately 80,000 elements.

\section{$J$-Integral Calculation Using the Contour Integral Method}

ABAQUS calculates the geometry-dependent SIFs using the contour integral method. ${ }^{22}$ In order to perform a contour integral analysis on a 3D crack, the crack front and crack direction must be defined. An example of the von Mises stress distribution along a crack front of arbitrary crack length $a\left(a_{0}<a<a_{1}\right)$ is shown in Fig. 2b. The contour integral analysis computed a $J$-integral at each node along the crack front, then the $J$-integrals were converted to the nondimensional SIF, $Y$, using Eqs. 1 and 2. Due to the numerical error from distortion of the edge meshes near a free surface, $Y$ varies slightly along the crack front and rises rapidly when approaching the cantilever surface. Similar effects were also reported by Sarrafi-Nour ${ }^{23}$ and Newman ${ }^{24}$ in FE-modeled chevron-notched specimens. Therefore, to eliminate the extreme values near free surfaces, $Y$ was taken as an average value from the midplane to approximately $80 \%(-0.4 \leq z / 2 \leq 0)$ of the crack front.

$$
\begin{gathered}
K=\sqrt{\frac{E J}{1-v^{2}}}, \\
Y=\frac{K B \sqrt{W}}{P},
\end{gathered}
$$



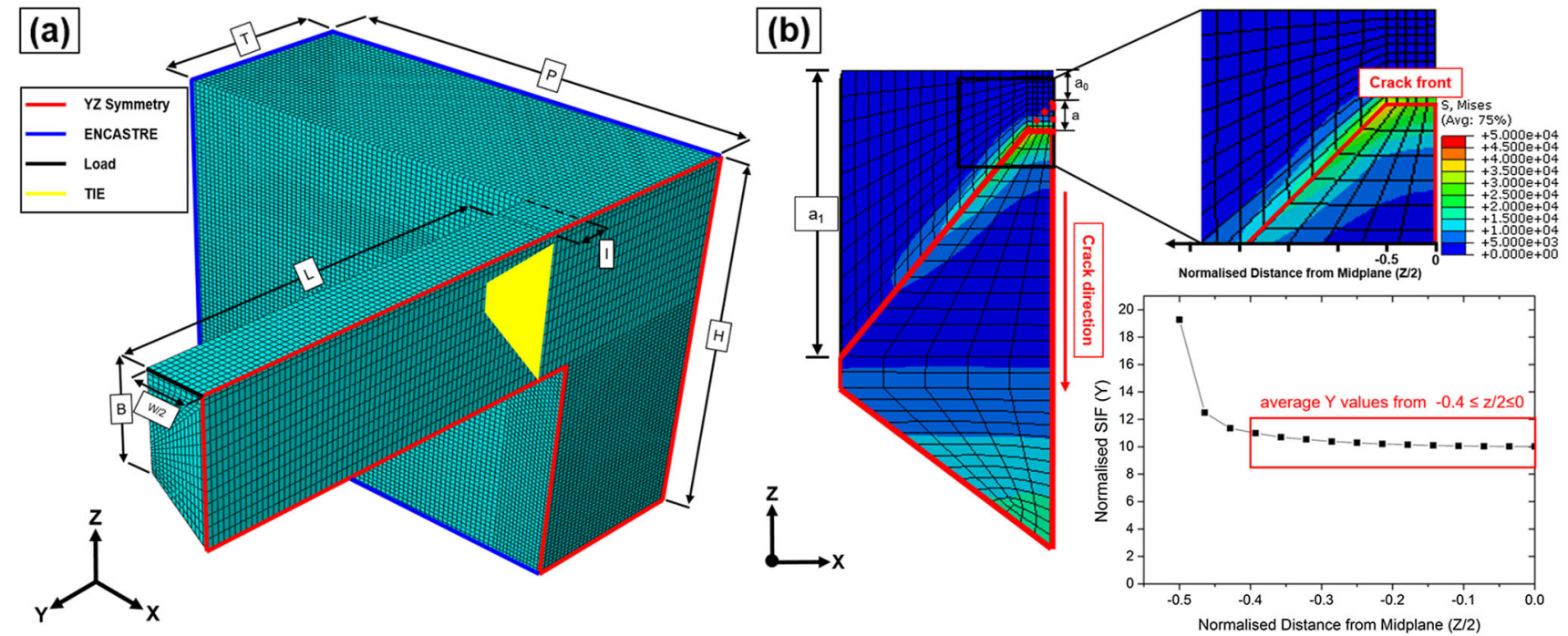

Fig. 2. (a) Typical meshed half-cantilever model with supporting base and boundary conditions. (b) Stress distribution of a half-chevron notch of crack length $a$, showing the variation of $Y$ along the crack front $(-0.5 \leq z / 2 \leq 0)$.

Table I. Typical dimensions of half-cantilever model (with supporting base)

\begin{tabular}{|c|c|c|c|c|c|c|c|c|}
\hline$\underline{L}(\mu \mathbf{m})$ & $\underline{B(\mu \mathbf{m})}$ & $\underline{W / 2}(\mu \mathrm{m})$ & $\underline{l(\mu \mathbf{m})}$ & $\underline{P}(\mu \mathbf{m})$ & $\underline{\boldsymbol{H}(\mu \mathbf{m})}$ & $\underline{T}(\mu \mathbf{m})$ & $\underline{a_{0}(\mu \mathrm{m})}$ & $a_{1}(\mu \mathrm{m})$ \\
\hline 9 & 3 & 1.5 & 1 & 12 & 12 & 5 & $0-0.9$ & $2.1-3$ \\
\hline
\end{tabular}

Table II. Test summary from two chevron-notched Si microcantilevers

\begin{tabular}{|c|c|c|c|c|c|c|c|c|c|}
\hline$\#$ & $\dot{\boldsymbol{L}}\left(\frac{\mu \mathbf{N}}{\mathbf{S}}\right)$ & $\underline{W(\mu \mathbf{m})}$ & $\underline{B}(\mu \mathbf{m})$ & $\underline{L}(\mu \mathbf{m})$ & $\underline{a_{0}(\mu \mathrm{m})}$ & $\underline{a_{1}(\mu \mathrm{m})}$ & $\underline{Y_{\text {min }}}$ & $\underline{\boldsymbol{P}_{\mathbf{c}}(\mu \mathbf{N})}$ & $\underline{K_{\text {Ic }}\left(M P a ~ m^{0.5}\right)}$ \\
\hline $\mathrm{A} 2$ & 5 & 2.9 & 2.8 & 9.1 & 0 & 1.56 & 3.1 & 825.5 & 0.82 \\
\hline $\mathrm{B} 2$ & 5 & 3.1 & 2.9 & 8.5 & 0 & 1.52 & 3.2 & 772.7 & 0.87 \\
\hline
\end{tabular}

where $E$ is the elastic modulus, $v$ is the Poisson's ratio, $P$ is the load at which the $J$-integral $(J)$ was calculated, and $B$ and $W$ are the cantilever thickness and width.

\section{Optimization of the Chevron Notch Geometry}

Quasistatic stable crack growth is a prerequisite for EPFM analysis, hence the chevron notch geometry should be optimized to ensure sufficiently stable crack growth up to the critical crack length $\left(\alpha_{\mathrm{c}}=a_{\mathrm{c}} / B\right)$. He and Evans ${ }^{25}$ first reported that the nondimensional SIFs were strong functions of the chevron tip $\left(\alpha_{0}=a_{0} / B\right)$ and base positions $\left(\alpha_{1}=a_{1} / B\right)$ but were only weakly dependent on the cantilever dimensions. Calomino et al. ${ }^{26}$ later reported that the primary effect of varying $\alpha_{0}$ and $\alpha_{1}$ is on the force required to initiate a sharp crack; e.g., a smaller $\alpha_{0}$ with larger $\alpha_{1}$ maximizes stable crack growth, but also increases the tendency for premature failure due to a narrower initial chevron ligament. For constant $\alpha_{0}$ and $\alpha_{1}$, the SIFs were almost independent of cantilever dimensions. Here, a series of $\mathrm{FE}$ simulations of various chevron geometries with increasing crack length were used to achieve notch geometries with sufficiently stable crack growth (taken as $a_{\mathrm{c}} \geq 0.5$ ). Dimensions used in the half-cantilever models are described in Table I. Isotropic, homogeneous, linear-elastic properties of tungsten were implemented $(E=410 \mathrm{GPa}$, $v=0.3) .{ }^{27}$ The variables in the simulations were the chevron tip position $\left(\alpha_{0}\right)$ and base position $\left(\alpha_{1}\right)$. The critical crack length at which crack extension becomes unstable $\left(\alpha_{c}\right), Y_{\min }$, and fit polynomials for $Y$ and $S$ versus normalized crack length $(\alpha)$ for four chevron notch geometries are provided in Table SI in the Electronic Supplementary Material. Due to the beam profile and small amounts of drift that are unavoidable during FIBing, it is impossible to make exact chevron notch geometries to match the FE simulations; hence, a set of notch geometries with sufficiently stable crack growth $\left(\alpha_{c} \geq 0.5\right)$ and stiffness drop with the expected crack growth $(\sim 1000 \mathrm{~N} / \mathrm{m})$ were selected to match with the 
actual microfracture tests. Crack lengths were calculated from stiffness changes measured in successive partial load-unload cycles, using FE simulations of stiffness with varying crack length, e.g. Fig. 3b, for calibration.

Chevron notches with low base position $\left(\alpha_{1} \leq 0.7\right)$ were not simulated, as redeposited materials can introduce curved edges that would reduce the triangular area and increase the likelihood of premature fracture. As an example, the SIF and stiffness plots for the chevron geometry $\left(\alpha_{0}=0.1\right.$, $\alpha_{1}=0.9$ ) used in $\mathrm{W}-1 \% \mathrm{Ta}$ cantilever tests are shown in Fig. 3.

\section{Validation Using Single-Crystal Silicon Microcantilevers}

Microfracture tests on single-crystal silicon with a (110) surface were used to validate the FE-calculated SIFs. Microcantilevers with (111) crack plane and chevron notch geometry of $\left(\alpha_{0}=0, \alpha_{1}=0.7\right)$ were fabricated via FIB, as shown in Fig. 4a, and deflected by using a nanoindenter to complete failure. The load-displacement curves are shown in Fig. $4 \mathrm{~b}$, and the fracture surfaces for cantilever A2 and B2 are shown in Fig. 4c and d, respectively. The LEFM plane-strain fracture toughness $\left(K_{\text {Ic }}\right)$ for a chevron-notched specimen can be calculated using the unstable fracture load $P_{\mathrm{c}}$ and the FE-calculated $Y_{\min }$ (for $\mathrm{Si}, E=169 \mathrm{GPa}$ and $v=0.21$ were used) via Eq. 3.

$$
K_{\mathrm{Ic}}=P_{\mathrm{c}} \frac{Y_{\min }}{B \sqrt{W}},
$$

where $B$ and $W$ are the cantilever thickness and width, $P_{\mathrm{c}}$ is the unstable fracture load, and $Y_{\min }$ is the minimum nondimensional SIF.

Due to the sharp apex and increasing crack front provided by the chevron geometry, a transition between stable and unstable crack growth is expected when the crack reaches $\alpha_{c}$ (at which point $Y$ reaches a minimum). Such a stable-to-unstable transition is visible on the fracture surfaces. The stress concentration at the chevron edges resulted in a slightly curved crack front. Cantilever geometry and test results are summarized in Table II. The fracture toughness values $\left(K_{\mathrm{Ic}}\right)$ calculated from the two chevron-notched $\mathrm{Si}$ microcantilevers $\left(\sim 0.85 \mathrm{MPa} \mathrm{m}^{0.5}\right)$ are in good agreement with the macroscopic $K_{\mathrm{Ic}}$ value for the same fracture plane $\left(\sim 0.9 \mathrm{MPa} \mathrm{m}{ }^{0.5}\right),{ }^{28}$ validating the FE-calculated SIFs from the microcantilever method.

\section{MICROFRACTURE TESTS OF W-1\%TA MICROCANTILEVERS}

Two geometries of $\mathrm{W}-1 \%$ Ta microcantilever were tested: (1) triangular unnotched cantilevers for measuring yield stress $\left(\sigma_{\mathrm{ys}}\right)$, which is required for the crack tip plastic zone size $\left(r_{\mathrm{y}}\right)$ estimation, and (2) pentagonal chevron-notched cantilevers for EPFM analysis of crack propagation.

\section{Triangular Microcantilevers}

Triangular microcantilevers were tested using the load partial-unload method, with a constant loading/unloading rate of $5 \mu \mathrm{N} / \mathrm{s}$. The load-displacement data were converted into a maximum stressstrain (SS) curve using simple beam theory via Eqs. 4 and 5. The elastic modulus, yield and flow stresses were extracted from the SS curve, shown in Fig. 5a. Due to the simple beam assumption, the stress-strain data were only valid up to the yield point. Most cycles showed an initial linear-elastic regime, followed by yielding and constant plastic flow. Yield was defined as occurring when the apparent secant modulus reduced to $90 \%$ of its initial value. The modulus measured from microcantilevers $(\sim 370 \mathrm{GPa})$ was slightly lower than literature values of $410 \mathrm{GPa}$. This is because simple
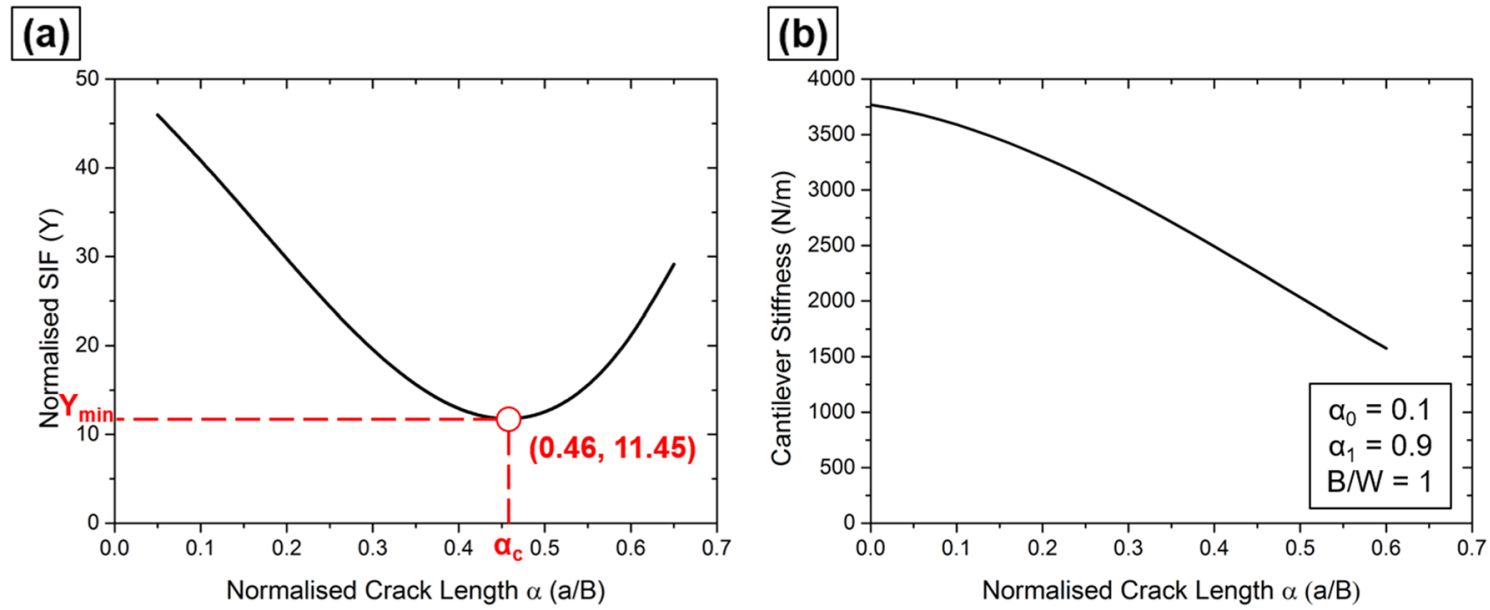

Fig. 3. (a) Stress intensity factor and (b) cantilever stiffness as a function of crack length calculated by FE analysis for the chevron geometry used in $\mathrm{W}-1 \% \mathrm{Ta}$ cantilever tests. The minimum in (a) is the crack length at which crack extension with increasing load changes from stable to unstable. 
Evaluation of Fracture Toughness Measurements Using Chevron-Notched Silicon and Tung-
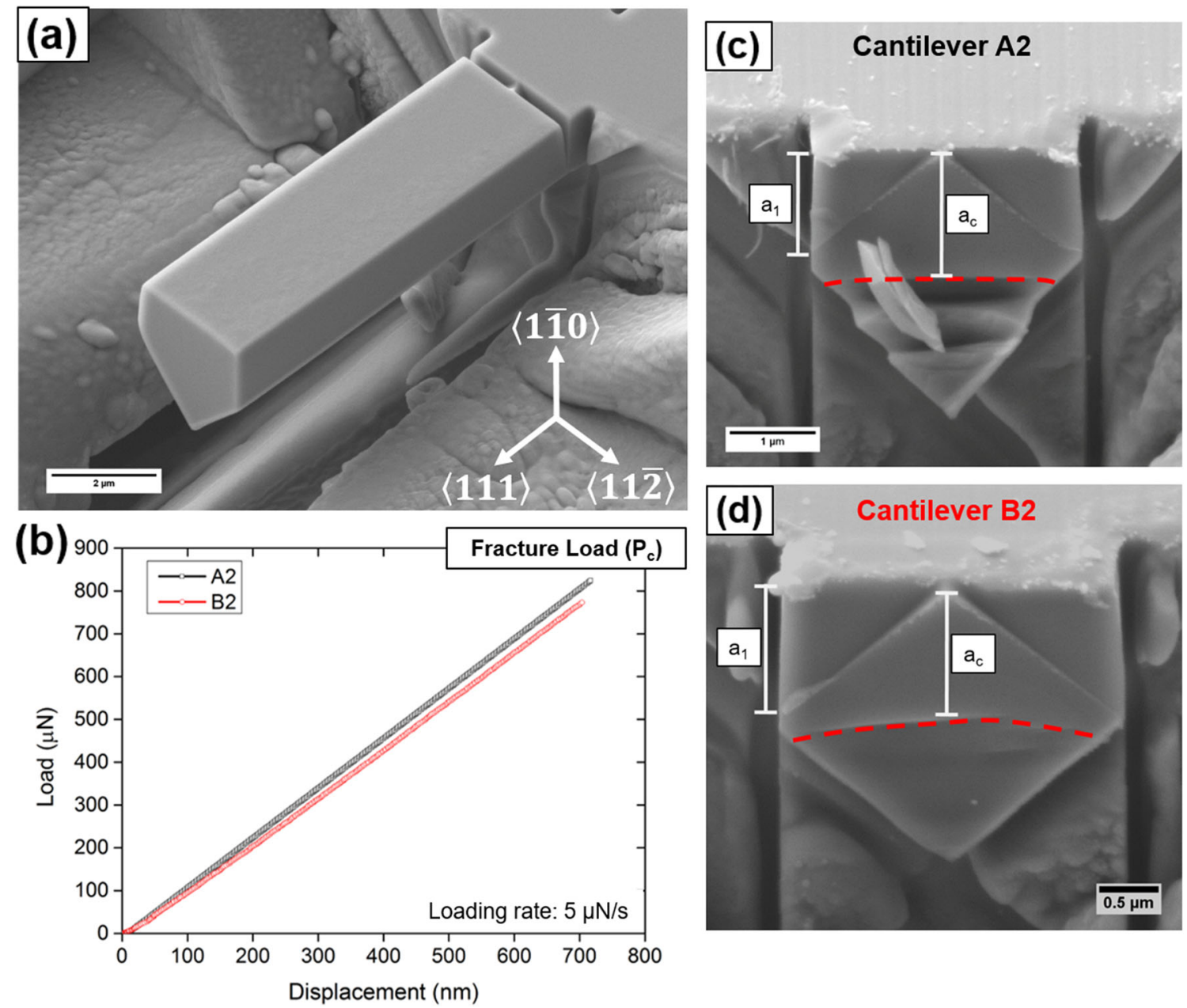

Fig. 4. (a) Chevron-notched Si microcantilevers with (111) crack plane, (b) load-displacement curves and (c, d) fracture surfaces of Si microcantilevers A2 and B2. Dotted red lines indicate the stable-to-unstable crack transition.

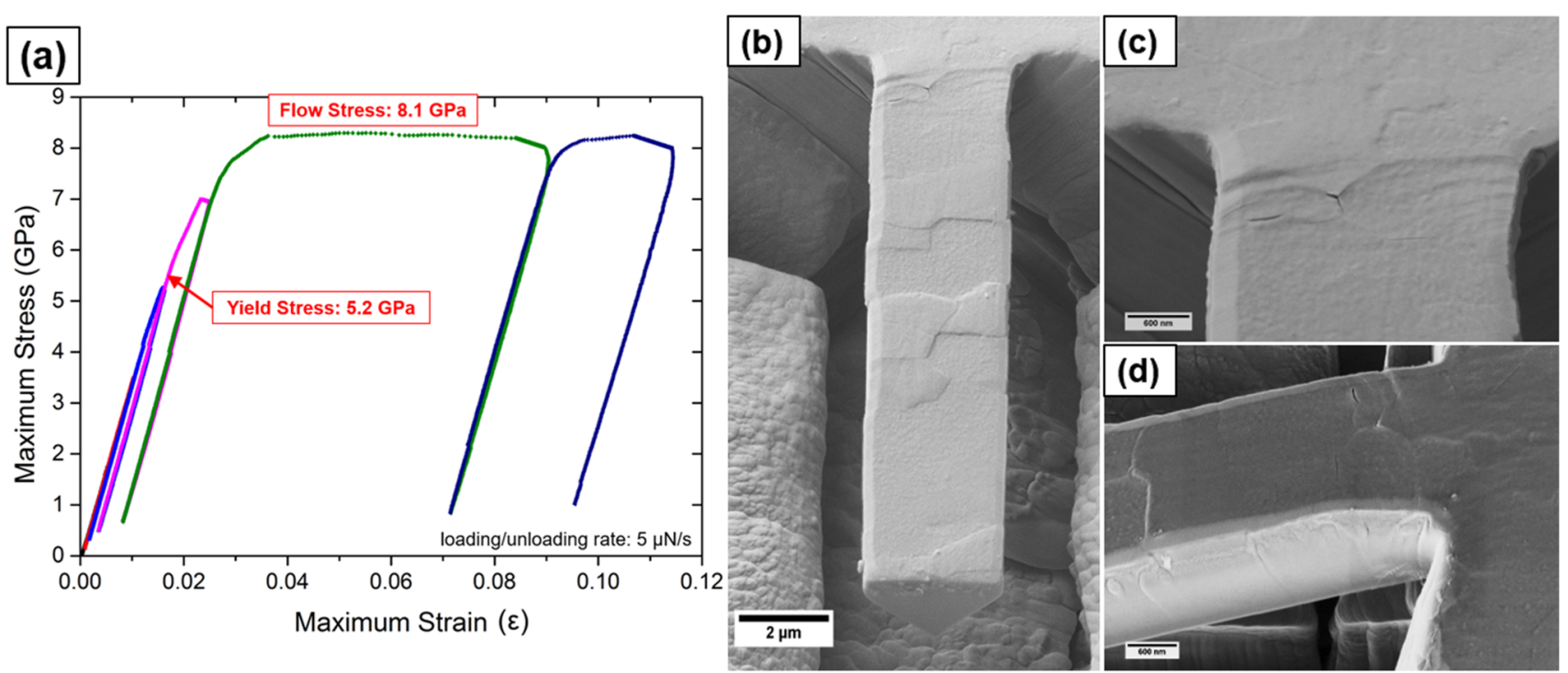

Fig. 5. (a) Cyclic stress-strain curve and (b-d) posttest SEM images of elastic-plastic triangular W-1\%Ta microcantilever. 
beam theory assumes a perfectly rigid cantilever base, whereas in real tests there will be small deflections in the base that increase the apparent compliance of the beam, as shown previously from the work by Armstrong et al. ${ }^{29}$

$$
\begin{gathered}
\sigma_{\max }=\frac{24 P L}{W B^{2}}, \\
\varepsilon_{\max }=\frac{2 B \delta}{L^{2}} .
\end{gathered}
$$

Slip traces from mobile dislocations were clearly observed at the top surface and bottom apex of the triangular cantilever, shown in the posttest SEM micrographs in Fig. 5b and d. Similar observations were reported by Gong et al. ${ }^{30}$ in pure titanium microcantilevers. In general, yield stresses measured from microcantilevers are strongly influenced by the cantilever thickness, showing a "smaller is stronger" trend. This is mainly due to the pile-up of mobile dislocations at the neutral axis and the lack of available dislocation sources for generating plasticity. ${ }^{31}$ The base deflection is not expected to influence the measured yield stress, as the yield point is defined using the "relative" drop of modulus. Results measured from two triangular W-1\% Ta and also data from $\mathrm{W}$ microcantilevers reported by Gibson et al. ${ }^{32}$ are summarized in Table III (uncertainties are propagated through dimension measurements). The higher $\sigma_{\mathrm{ys}}$ in $\mathrm{W}-1 \% \mathrm{Ta}$ can be attributed to the strengthening effect from the tantalum addition. ${ }^{33}$

\section{Chevron-Notched Pentagonal Microcan- tilevers}

All load partial-unload tests were performed using a G200 Nanoindenter (KLA, Milpitas, USA) in closed-loop, load-controlled mode. The load-displacement curves were corrected for the indenter tip embedding. Details regarding the corrections are provided in Table SII in the Electronic Supplementary Material. SEM/EBSD images, dimensions, and test parameters of two cantilevers are given in Fig. 6 and Table IV.

The load-displacement curves of two cantilevers, W/Ta-A and W/Ta-B, are shown in Fig. 7a and d. Both cantilevers were loaded incrementally until instability. A significant amount of nonlinear deformations was observed in the later cycles, which was associated with stable crack growth and plasticity.
Cantilever stiffness values were calculated using the corrected load-displacement curves, and are shown in Fig. $7 \mathrm{~b}$ and e. Even with the tip embedding correction, the stiffness values calculated from initial cycles are slightly lower than the FE-estimated cantilever stiffness $(\alpha=0$, indicated as black line showing the "initial" stiffness value without any crack growth). This may be due to the fact that the polynomial fit used to estimate the tip embedding depth does not take into account the hardness of the individual grain that the tip is in contact with, hence the total embedding depth is not fully corrected for due to local hardness variations between grains. "Stiffness drop" values for two cantilevers were calculated as the difference between the stiffness of the unfractured cantilever (notched but crack not yet initiated) and the final unloading cycle stiffness (prior to unstable fracture). The unstable fracture load, total stiffness drop, and extent of stable crack growth (calculated using the stiffness versus crack length relationship from the FE simulations), are summarized in Table V. Fracture surfaces of the two cantilevers are shown in Fig. 7c and $\mathrm{f}$.

In cantilever W/Ta-A, the fracture surface was mostly dominated by ductile dimple-like features. In cantilever W/Ta-B, the surface of cracks initiated at the chevron apex was also dominated by ductile dimple-like features, which changed to brittle cleavage-like features as the crack propagated. Crack lengths at the stable-to-unstable transition calculated from stiffness drops for two cantilevers are around $520 \mathrm{~nm}$, significantly less than the crack length expected from the FE-estimated crack length $\alpha_{\mathrm{c}}(\sim 1380 \mathrm{~nm})$. Figure 8 shows another tested chevron-notched W-1\% Ta microcantilever without any apparent stable crack growth. Significant tearing of the ductile ligaments was observed at the chevron apex where the cracks initiated, which can be related to additional plastic work stored in the cantilever and possibly led to premature failure; it may be that the crack path followed a grain boundary instead of the chevron ligament. The load-controlled nature of the nanoindenter also contributes to the early termination of stable crack growth. Any nonlinear events, e.g., plasticity or fracture, will force the indenter to move abruptly until the maximum load is reached. One should still expect reasonable elastic-plastic fracture properties to be calculated from those cantilevers, since evidence of stable crack growth is clearly visible from

\begin{tabular}{|c|c|c|c|}
\hline Triangular cantilever & Thickness $(\mu \mathrm{m})$ & Elastic modulus (GPa) & Yield stress (GPa) \\
\hline Cantilever 1 (W-1\%Ta) & $2.8 \pm 0.1$ & $367 \pm 35$ & $5.2 \pm 0.2$ \\
\hline Cantilever 2 (W-1\%Ta) & $2.6 \pm 0.1$ & $370 \pm 28$ & $5.1 \pm 0.3$ \\
\hline Gibson (W) & $2 \pm 0.2$ & $418 \pm 86$ & $2.7 \pm 0.4$ \\
\hline
\end{tabular}

Table III. Moduli and yield stresses obtained from W-1\%Ta and W microcantilevers [32] 

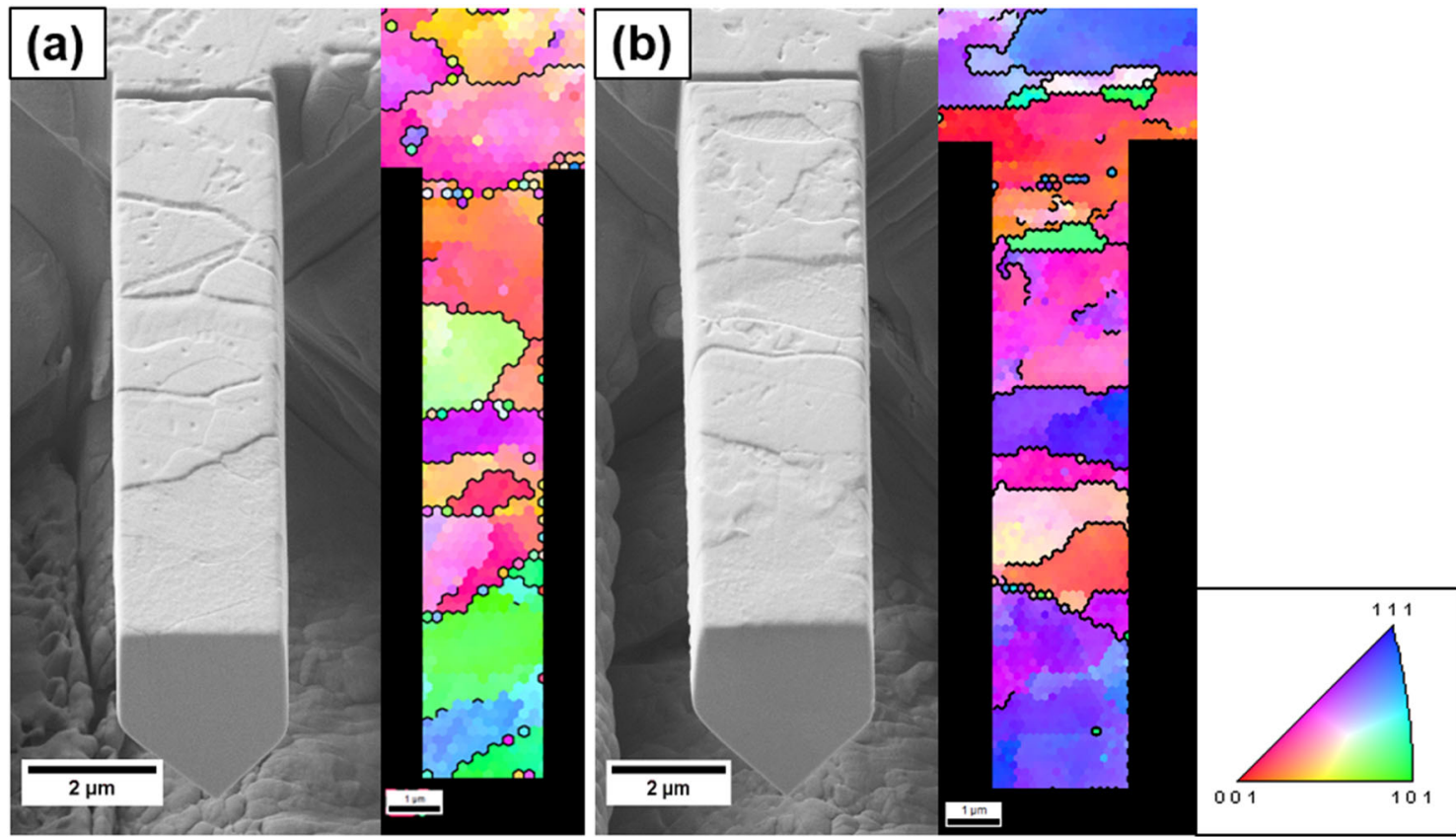

Fig. 6. SEM/EBSD images of chevron-notched microcantilevers: (a) W/Ta-A and (b) W/Ta-B.

Table IV. Dimensions and test parameters for two W-1\% Ta cantilevers

\begin{tabular}{|c|c|c|c|c|c|c|c|c|c|c|}
\hline Cantilever & $\underset{(\mu \mathbf{m})}{L}$ & $\begin{array}{c}B \\
(\mu \mathbf{m})\end{array}$ & $\begin{array}{c}W \\
(\mu \mathbf{m})\end{array}$ & $\begin{array}{c}S \\
(\mu \mathbf{m})\end{array}$ & $\underset{B}{\alpha_{0}\left(a_{0} /\right.}$ & $\begin{array}{c}\alpha_{1}\left(a_{1} /\right. \\
B)\end{array}$ & $\begin{array}{c}\dot{\boldsymbol{L}}(\boldsymbol{\mu} \mathbf{N} / \\
\mathbf{s})\end{array}$ & $\begin{array}{c}\text { Load Increment } \\
(\mu \mathrm{N})\end{array}$ & $\begin{array}{l}\text { Hold } \\
(s)\end{array}$ & $\underset{\%}{\text { Unload }}$ \\
\hline W/Ta-A & 11.2 & 3 & 3 & 0.5 & 0.1 & 0.9 & 5 & 50 & 30 & 50 \\
\hline W/Ta-B & 11.2 & 3 & 3 & 0.5 & 0.1 & 0.9 & 5 & 50 & 30 & 50 \\
\hline
\end{tabular}

the fracture surfaces. In summary, the posttest SEM fractography showed that the region of stable crack growth in the chevron-notched W$1 \%$ Ta microcantilevers was accompanied by extensive plasticity and should be taken into account in later EPFM analysis.

\section{Elastic-Plastic Fracture Mechanical Analysis of W-1\% Ta Microcantilevers}

Elastic-plastic fracture mechanical (EPFM) analysis was used to calculate the fracture resistance curves ( $\mathrm{R}$ curve) for the two $\mathrm{W}-1 \% \mathrm{Ta}$ cantilevers. Using the $J$-integral, ${ }^{34}$ the analysis takes into account both the elastic and plastic work that accompanies crack extension. Calculation of the $J$ integrals requires information on the crack length and work of fracture (WOF) at each loading cycle, which were determined by analysis of data from the load partial-unload cycles, as described below.

The $J$-integral at each crack length $J_{(i)}$ is divided into both elastic and plastic components, as shown in Eq. 7. The elastic component $J_{\mathrm{el}(i)}$ was calculated using the LEFM equation described in Eq. 6 and the first part of Eq. 7. The analysis assumes that the crack front is straight, and crack surfaces are fully opened and continuous, e.g., no bridging ligaments. The plastic component $J_{\mathrm{pl}(i)}$ was calculated in terms of the work of fracture (WOF), using the area under the load-displacement curve $A_{\mathrm{pl}(i)}$, and the area of crack surface created during each cycle, described in the latter half of Eq. 7. Due to the chevron notch geometry, the crack surface areas were calculated conveniently using the crack length $a_{(i)}$ estimated from the stiffness drop and the corresponding crack front $B_{(i)}$. The constant $\eta$ was set to 2 to take into account the two crack surfaces. ${ }^{35}$ For ease of comparison with macroscopic $K$ values, the $J$-integral at crack instability was converted to the conditional fracture toughness $K_{\mathrm{Qc}}$ using Eq. 8 (assuming plane-strain condition). A schematic load-displacement curve, which illustrates the EPFM analysis, and the calculated parameters are provided in Tables SIII and SIV in the Electronic Supplementary Material. The microscopic $R$-curves for the two cantilevers, obtained prior to instability, are shown in Fig. 9.

$$
K_{(i)}=\frac{P_{(i)}}{B \sqrt{W}} Y_{(i)}
$$




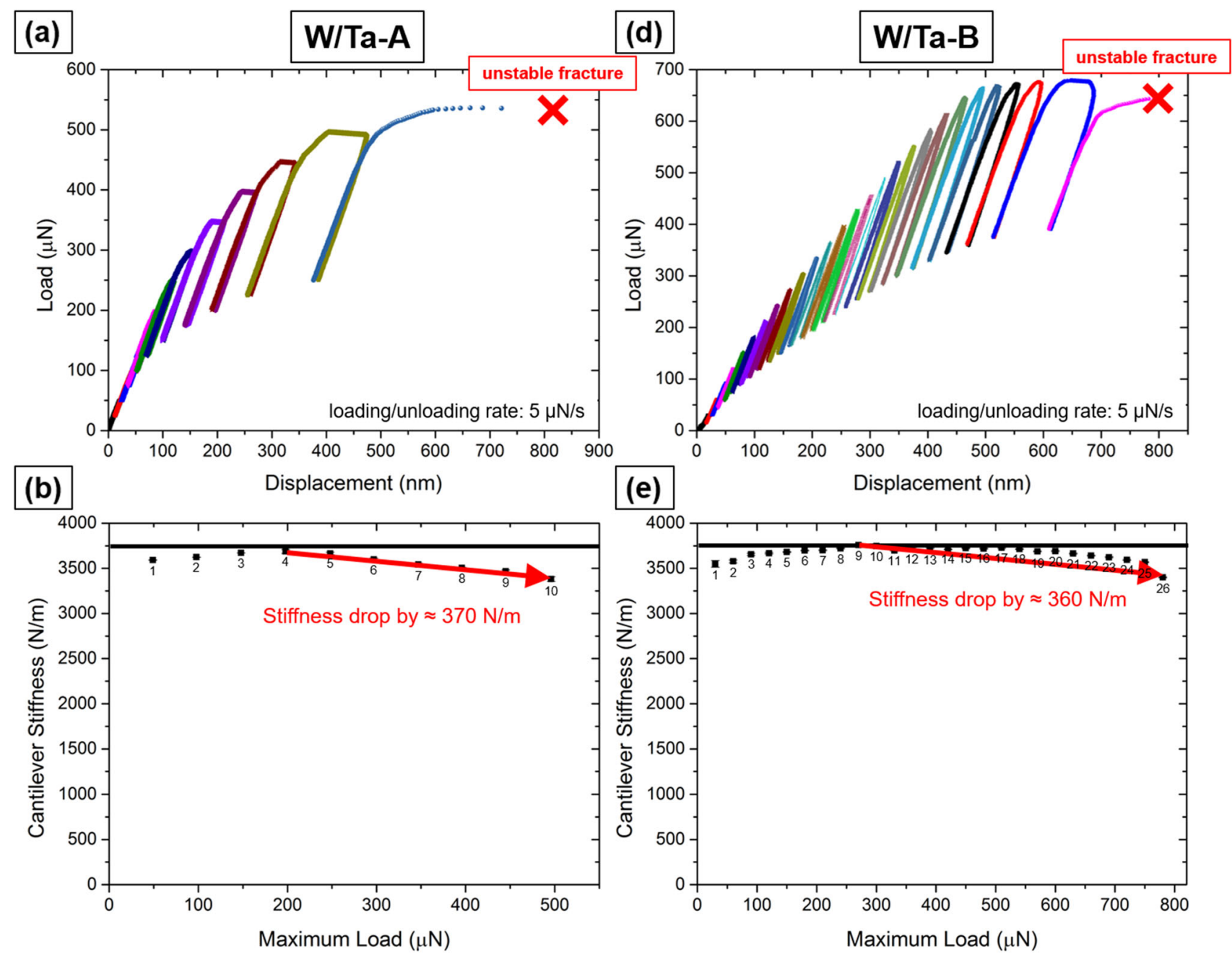

(c)

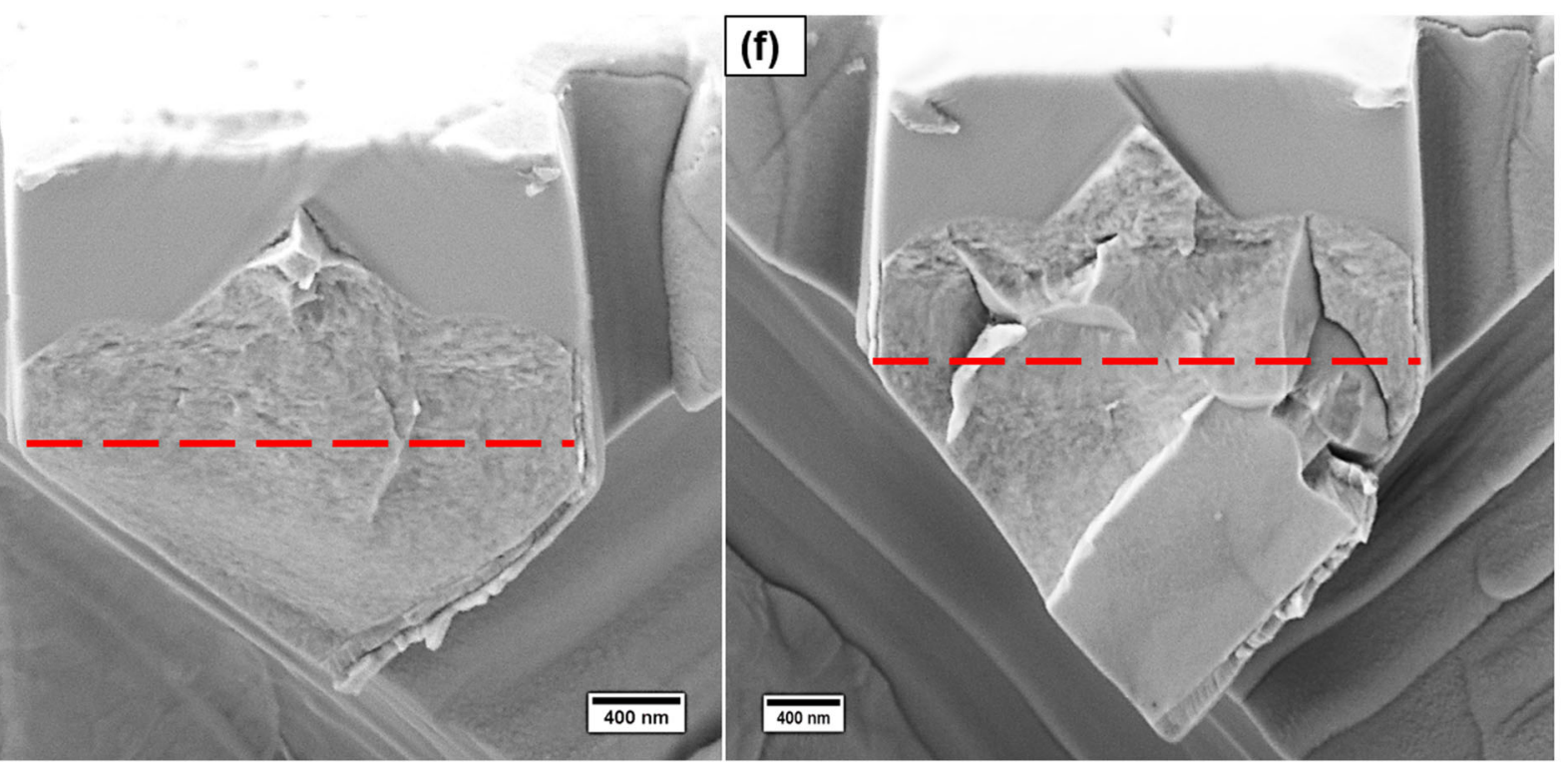

Fig. 7. Load-displacement curves, cantilever stiffness versus maximum load (number indicates load-unload cycle) and fracture surfaces for cantilever W/Ta-A $(a-c)$ and W/Ta-B $(d-f)$. The red dotted line on the fracture surfaces indicates the stable crack length expected from FE simulation. Note that a smaller load increment $(30 \mu \mathrm{N})$ for cantilever B was used. 
Table V. Test summary of cantilever W/Ta-A and W/Ta-B

\begin{tabular}{|c|c|c|c|c|}
\hline Cantilever & $\begin{array}{c}\text { Unstable fracture } \\
\text { load }(\mu \mathrm{N})\end{array}$ & $\begin{array}{c}\text { Total stiffness drop } \\
(\mathrm{N} / \mathrm{m})\end{array}$ & $\begin{array}{c}\text { Stable crack length } \\
(\mathbf{n m})\end{array}$ & $\begin{array}{c}\text { Expected stable crack } \\
\text { length }(\mathrm{nm})\end{array}$ \\
\hline $\begin{array}{l}\text { W/Ta-A } \\
\text { W/Ta-B }\end{array}$ & $\begin{array}{l}536 \\
643\end{array}$ & $\begin{array}{l}370 \pm 4 \\
360 \pm 5\end{array}$ & $\begin{array}{l}525 \pm 10 \\
507 \pm 12\end{array}$ & $\begin{array}{l}1380 \\
1380\end{array}$ \\
\hline
\end{tabular}

The total stiffness drop and stable crack length were measured from the load partial-unload cycles, and the expected stable crack length were calculated from FE models of similar geometry.
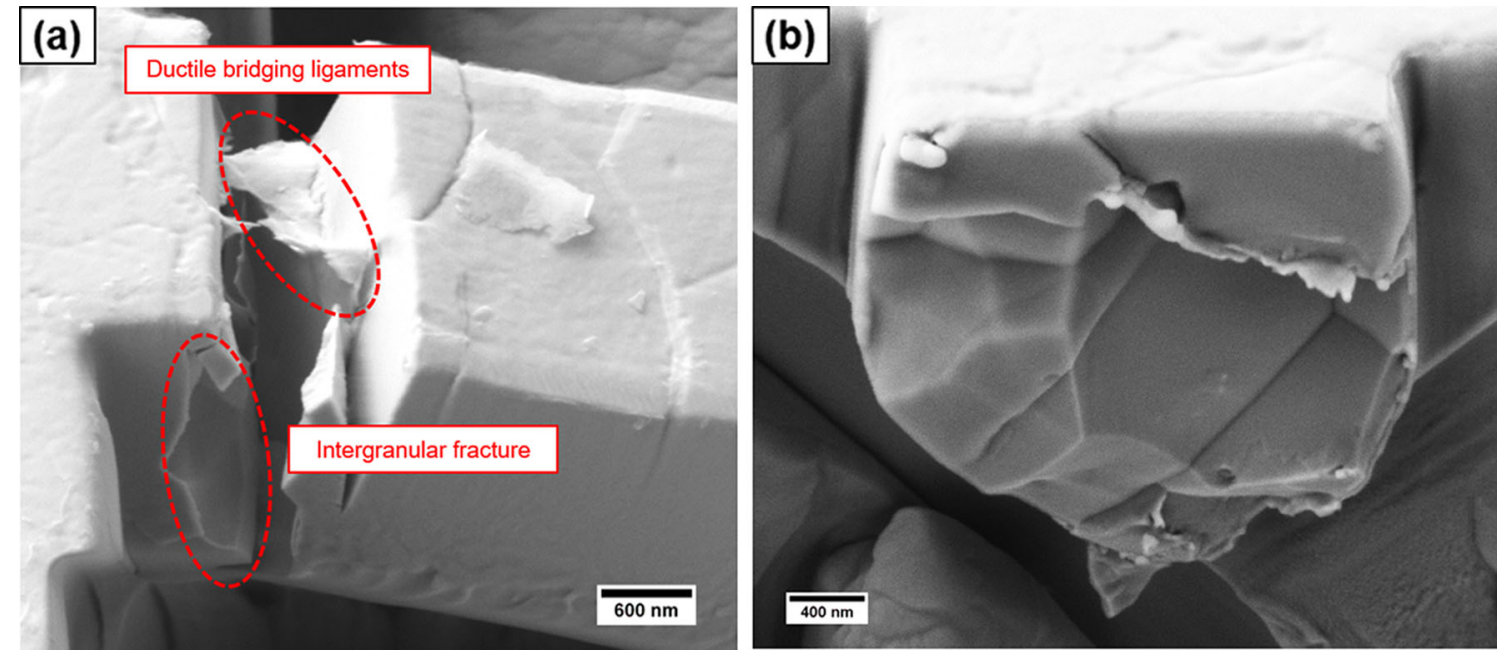

Fig. 8. (a) Posttest SEM of a chevron-notched W-1\%Ta cantilever without stable crack growth, and (b) fractography showing ductile ligament followed by brittle fracture.

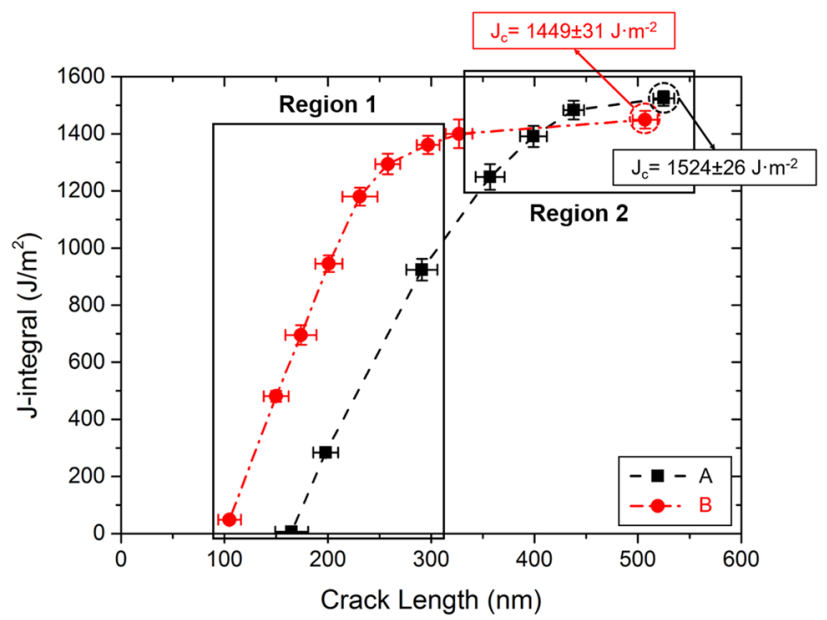

Fig. 9. $R$-curves for cantilever W/Ta-A and W/Ta-B. Crack initiation and stable crack growth regimes are labeled as region 1 and 2 , respectively.

$$
\begin{aligned}
J_{(i)} & =J_{i, \text { elastic }}+J_{i, \text { plastic }} \\
& =\frac{K_{(i)}^{2}\left(1-v^{2}\right)}{E}+\frac{2 \eta A_{\mathrm{pl}(i)}}{\left[B_{(i)} a_{(i)}-B_{(i-1)} a_{(i-1)}\right]}
\end{aligned}
$$

\begin{tabular}{|c|c|c|}
\hline Cantilever & $J_{c}\left(J / \mathbf{m}^{2}\right)$ & $K_{\mathbf{Q c}}\left(\mathbf{M P a ~ m}^{0.5}\right)$ \\
\hline W/Ta-A & $1524 \pm 26$ & $26.2 \pm 2.3$ \\
\hline $\mathrm{W} / \mathrm{Ta}-\mathrm{B}$ & $1447 \pm 31$ & $25.4 \pm 2.3$ \\
\hline
\end{tabular}

Table VI. EPFM results for two cantilevers

In region 1 of Fig. 9, both curves show a steep initial slope. In the semibrittle tungsten, crack initiation at the chevron apex was associated with extensive ductile tearing shown previously in Fig. 8; it is likely that the plastic work calculated during the initial cycles was mostly from the ductile tearing rather than the actual crack extension. In region 2 , $J$ increases gradually with crack extension, and it is assumed that the work is now mainly associated with generating new surfaces, and the local plastic work around the crack tip. This would cause the rather flat $R$-curve that is observed. The $J$ values attained just before crack instability were used to describe the critical condition for crack instability, 
and the EPFM $J_{\mathrm{c}}$ and $K_{\mathrm{Qc}}$ values obtained for the two cantilevers are summarized in Table VI.

\section{DISCUSSION}

\section{Room-Temperature Fracture Resistance of Tungsten}

Similar fracture resistance behavior of tungsten has also been reported elsewhere. Gludovatz et al. ${ }^{36}$ reported a macroscopic $R$-curve behavior in industrial-grade polycrystalline tungsten. They concluded that the increasing fracture resistance was due to the connection between different cleavage planes in adjacent grains and crack bridging effects. Localized plasticity near the vicinity of the crack path was also observed, which contributed to the fracture resistance during initial crack growth. In this study, it is unlikely that connection between cleavage planes in adjacent grains contributed to the microscopic $R$-curve behavior, as the microcantilevers typically only have one grain throughout the entire thickness. Ast et al. ${ }^{37}$ similarly reported $R$-curve behavior in straight-notched single-crystal tungsten microcantilevers, which was found to be strongly dependent on the cantilever size, due to the presence of a plastic strain gradient and crack tip plasticity. Cantilevers with intermediate thickness of $9 \mu \mathrm{m}$ exhibited the highest fracture resistance, whereas in larger cantilevers, a reduction of fracture resistance was due to the less pronounced plastic strain gradient. It should be noted that even the highest $J$ value at crack instability $\left(\sim 800 \mathrm{~J} / \mathrm{m}^{2}\right)$ in their straight-notched cantilevers was still significantly smaller than the value obtained from the chevron-notched microcantilevers $\left(1500 \mathrm{~J} / \mathrm{m}^{2}\right)$. One possible reason for this discrepancy is that the straight-notched cantilevers are more susceptible to unstable fracture due to notch bluntness, which may prevent full development of crack tip plasticity.

The microscopic EPFM $K_{\mathrm{Qc}}$ values obtained in this study are approximately five times higher than the macroscopic LEFM $K_{\text {Ic }}$ of $\sim 5 \mathrm{MPa} \mathrm{m}^{0.5}$. $^{38}$ The EPFM analysis assumes that all plastic work contributed to the stable crack growth. This is not necessarily the case, as redundant plastic deformation will occur in the microcantilevers: gross yielding (i.e., dislocation traces), crack tip blunting, and ductile tearing of bridging ligaments were observed. Hence, it is expected that the microscopic $K_{\mathrm{Qc}}$ overestimates the true fracture toughness due to this contribution from size-dependent plasticity. Furthermore, evaluation of the $K_{\mathrm{Qc}}$ by EPFM requires a critical ratio between the specimen size and the crack tip plastic zone to be exceeded, to ensure sufficient stress triaxiality at the crack tip. $^{35}$ For a valid $K_{\mathrm{Qc}}$ measurement, ASTM E1820 defines a minimum specimen size requirement using Eq. 9, ${ }^{39}$ which is based on the effect of yield stress on the plastic zone size.

$$
B, b_{0} \geq \frac{\lambda J_{Q}}{\sigma_{\mathrm{ys}}},
$$

where $B$ is the specimen thickness, $b_{\mathrm{o}}$ is the initial ligament size, $\lambda$ is a dimensionless constant of 100 , and $\sigma_{\mathrm{ys}}$ is the yield stress

Taking cantilever A as an example, using $\sigma_{\mathrm{ys}}$ of $5.2 \mathrm{GPa}$ (from unnotched triangular cantilever) and $J_{c}$ of $1524 \mathrm{~N} / \mathrm{m}$, the minimum thickness required would be approximately $32 \mu \mathrm{m}$. Similarly, the minimum thickness for cantilever B is approximately $28 \mu \mathrm{m}$. Here, the cantilever thickness is only about $3 \mu \mathrm{m}$, hence it is suggested that EPFM analysis overestimates the fracture toughness and the true value will lie between the LEFM-calculated lower bound and EPFM-calculated higher bound.

\section{Crack Stability in Chevron-Notched Microcantilevers}

The chevron-notched microcantilever is intended to introduce a sharp precrack during loading, which will grow stably due to the increasing crack front until the SIF reaches its minimum. The results in this work, however, showed a significant deviation between the FE-predicted and experimentally measured extent of stable crack growth. For the Si cantilever, the load-displacement curves showed almost no nonlinearity, which should have been observed if the expected stable crack extension had occurred. The fracture toughness in the brittle $\mathrm{Si}$ beams was therefore evaluated using the predicted condition for instability and LEFM. For the W$1 \%$ Ta cantilevers, the stable crack length measured from the change in cantilever stiffness was significantly less than the FE-predicted length, suggesting that crack instability is strongly influenced by the plastic collapse of the ligaments. The chevron notches in this work have a finite thickness of approximately $\sim 30 \mathrm{~nm}$ due to the limitation of the FIB aperture size, which was neglected in the FE simulations. The thicker chevron notch would also contribute to the additional load for crack initiation, and discourage stable propagation.

\section{CONCLUSION}

The aim of this work is to investigate the fracture behavior of semibrittle W-1\%Ta alloy using microfracture experiments. This was done by introducing a chevron notch to promote precracking and stable crack growth. A modified load-controlled load partial-unload method was used for static cantilever stiffness measurements. The fracture toughness measured from chevron-notched $\mathrm{Si}$ single-crystal microcantilevers was in good agreement with macroscopic values, which validated the specimen design. Subsequently, chevron-notched microcantilevers were used to measure the fracture resistance ( $R$-curve) of semibrittle W-1\% Ta using elastic-plastic fracture mechanical (EPFM) analysis. The conditional fracture toughness value $\left(K_{\mathrm{Qc}}\right)$ at crack instability was significantly higher than the macroscopic $K_{\mathrm{Ic}}$, and this is due to plasticity, including the larger crack tip plastic zone to 
specimen size ratio and the additional plastic work required to initiate fracture from chevron notches of finite thickness. It is therefore suggested that EPFM analysis calculates a higher bound value for the fracture toughness of semibrittle materials.

\section{ACKNOWLEDGEMENTS}

B.-S.L. thanks the EPSRC Platform Grant (EP/ P001645/1) for financially supporting this research. D.E.J.A. would like to acknowledge his RAENg Fellowship.

\section{OPEN ACCESS}

This article is distributed under the terms of the Creative Commons Attribution 4.0 International License (http://creativecommons.org/licenses/by/4.0/ ), which permits unrestricted use, distribution, and reproduction in any medium, provided you give appropriate credit to the original author(s) and the source, provide a link to the Creative Commons license, and indicate if changes were made.

\section{ELECTRONIC SUPPLEMENTARY MATERIAL}

The online version of this article (https://doi.org/ 10.1007/s11837-019-03696-1) contains supplementary material, which is available to authorized users.

\section{REFERENCES}

1. M. Sebastiani, K.E. Johanns, E.G. Herbert, and G.M. Pharr, Curr. Opin. Solid State Mater. Sci. 19, 324 (2015).

2. G. Dehm, B.N. Jaya, R. Raghavan, and C. Kirchlechner, Acta Mater. 142, 248 (2018).

3. J. Ast, M. Ghidelli, K. Durst, M. Goeken, M. Sebastiani, and A.M. Korsunsky, Mater. Des. 173, 107762 (2019).

4. D.E.J. Armstrong, A.J. Wilkinson, and S.G. Roberts, Philos. Mag. Lett. 91, 394 (2011).

5. D.E.J. Armstrong, C.D. Hardie, J.S.K.L. Gibson, A.J. Bushby, P.D. Edmondson, and S.G. Roberts, J. Nucl. Mater. 462, 374 (2015)

6. D. Di Maio and S.G. Roberts, J. Mater. Res. 20, 299 (2005).

7. K. Matoy, T. Detzel, M. Müller, C. Motz, and G. Dehm, Surf Coat. Technol. 204, 878 (2009).

8. S. Massl, W. Thomma, J. Keckes, and R. Pippan, Acta Mater. 57,1768 (2009).

9. D.E.J. Armstrong, A.S.M.A. Haseeb, S.G. Roberts, A.J. Wilkinson, and K. Bade, Thin Solid Films 520, 4369 (2012).

10. M. Sebastiani, K.E. Johanns, E.G. Herbert, F. Carassiti, and G.M. Pharr, Philos. Mag. 95, 1928 (2015).
11. S. Liu, J.M. Wheeler, P.R. Howie, X.T. Zeng, J. Michler, and W.J. Clegg, Appl. Phys. Lett. 102, 1 (2013).

12. N.B. Jaya, V. Jayaram, and S.K. Biswas, Philos. Mag. 92, 3326 (2012).

13. M.J. McLean, C.A. Wade, M. Watanabe, and R.P. Vinci, Exp. Mech. 54, 685 (2014).

14. B.N. Jaya, C. Kirchlechner, and G. Dehm, J. Mater. Res. 30, 686 (2015).

15. K. Hayashi, S. Tsujimoto, Y. Okamoto, and T. Nishikawa, J. Soc. Mater. Sci. Jpn. 40, 405 (1991).

16. S. Wurster, C. Motz, and R. Pippan, Philos. Mag. 92, 1803 (2012).

17. F. Iqbal, J. Ast, M. Göken, and K. Durst, Acta Mater. 60, 1193 (2012).

18. J. Ast, M.N. Polyakov, G. Mohanty, J. Michler, and X. Maeder, Mater. Sci. Eng., A 710, 400 (2018).

19. G. Sernicola, P. Patel, J.R. Kermode, D.S. Balint, T.B. Britton, and F. Giuliani, Nat. Commun. 8, 108 (2017).

20. M.G. Mueller, V. Pejchal, G. Žagar, A. Singh, M. Cantoni, and A. Mortensen, Acta Mater. 86, 385 (2015).

21. Y. Huh, K.J. Hong, and K.S. Shin, Microsc. Microanal. 19, 33 (2013)

22. ABAQUS/CAE User's Manual 6.14, Dassault Systèmes Simulia Corp, (2009).

23. G.R. Sarrafi-Nour, T.W. Coyle, and T. Fett, Eng. Fract. Mech. 59, 439 (1998).

24. J.C. Raju and I.S. Newman, Chevron-Notched Specimens Tests and Stress Analysis 8, 33, (1984).

25. A.G. He and M.Y. Evans, Proceedings of the 22nd Fracture Mechanics National Symposium 1, 471, (1990).

26. A.M. Calomino and L.J. Ghosn, Int. J. Fract. 72, 311 (1995),

27. A.J. Harris, B.D. Beake, D.E.J. Armstrong, and M.I. Davies, Exp. Mech. 57, 1115 (2017).

28. J. Samuels and S.G. Roberts, Proc. R. Soc. A Math. Phys. Eng. Sci. 421, 10 (1989).

29. D.E.J. Armstrong, A.J. Wilkinson, and S.G. Roberts, J. Mater. Res. 24, 3268 (2009).

30. J. Gong and A. Wilkinson, Philos. Mag. Lett. 90, 503 (2010).

31. E. Tarleton, D.S. Balint, J. Gong, and A.J. Wilkinson, Acta Mater. 88, 271 (2015).

32. J. Gibson, D. Armstrong, and S. Roberts, Phys. Scr. T159, 14056 (2014)

33. Z. Wang, Y. Yuan, K. Arshad, J. Wang, Z. Zhou, J. Tang, and G.-H. Luo, Fusion Eng. Des. 125, 496 (2017)

34. J.R. Rice, J. Appl. Mech. 35, 379 (1968).

35. T. L. Anderson, Fracture Mechanics: Fundamentals and Applications, 3rd ed. (2005).

36. B. Gludovatz, S. Wurster, A. Hoffmann, and R. Pippan, Eng. Fract. Mech. 100, 76 (2013).

37. J. Ast, M. Göken, and K. Durst, Acta Mater. 138, 198 (2017).

38. S. Wurster, B. Gludovatz, A. Hoffmann, and R. Pippan, J. Nucl. Mater. 413, 166 (2011).

39. ASTM International, ASTM E1820-13 Standard Test Method for Measurement of Fracture Toughness, West Conshohocken, PA, USA, (2013).

Publisher's Note Springer Nature remains neutral with regard to jurisdictional claims in published maps and institutional affiliations. 